\title{
Correction to: Spectrum of diagnostic errors in cervical spine trauma imaging and their clinical significance
}

\author{
Francesco Alessandrino ${ }^{1}$ (D) Christopher M. Bono ${ }^{2,3}$. Christopher A. Potter ${ }^{1}$. \\ Mitchel B. Harris ${ }^{2,3} \cdot$ Aaron D. Sodickson $^{1} \cdot$ Bharti Khurana $^{1}$
}

Published online: 26 April 2019

(C) American Society of Emergency Radiology 2019

\section{Correction to: Emergency Radiology 2019 https://doi.org/10.1007/s10140-019-01685-0}

The published version of this article unfortunately contained a mistake. Author given and family name Alessandrino Francesco was incorrectly interchanged. The correct presentation is given above. The original article has been corrected.

Publisher's note Springer Nature remains neutral with regard to jurisdictional claims in published maps and institutional affiliations.

The online version of the original article can be found at https://oi.org/ 10.1007/s10140-019-01685-0

Francesco Alessandrino

falessandrino@bwh.harvard.edu

1 Department of Radiology, Brigham and Women's Hospital, Harvard Medical School, 75 Francis Street, Boston, MA 02115, USA

2 Department of Orthopedic Surgery, Brigham and Women's Hospital, Harvard Medical School, 75 Francis Street, Boston, MA 02115, USA

3 Department of Orthopedic Surgery, Massachusetts General Hospital, Harvard Medical School, 55 Fruit Street, Boston, MA 02114, USA 